\title{
Using selective interference to investigate spatial memory representations*
}

\author{
TIMOTHY A. SALTHOUSE $\dagger$ \\ Human Performance Center, University of Michigan, Ann Arbor, Michigan 48104
}

\begin{abstract}
Two experiments used a selective interference procedure in an attempt to determine whether nonverbal visual stimuli were represented in memory in a verbal or spatial format. A spatial representation was clearly implicated. In both experiments, Ss were required to remember either the positions or the identities of seven target items in a 25-item array. During the retention interval for that information, Ss attempted to recognize schematic face or airplane photograph stimuli in a same-different memory task. Memory performance on one or both tasks was greatly impaired when the recall task involved position or spatial information, but was either much less or not at all affected by an identity or verbal information recall task. Because of the selective nature of the interference and on the basis of certain correlational evidence, the experimental results were also interpreted as providing support for the notion that verbal and spatial information are stored and processed in separate information-processing systems.
\end{abstract}

Do visual images exist? Can people use spatial or visual codes to remember nonverbal material? Also, to what extent are spatial and verbal information stored and processed in separate memory and processing systems? The experiments in the present report attempt to provide answers to these questions.

The primary goal in the research was to determine the nature of the short-term memory code for nonverbal visual stimuli. The basic issue may be stated in the following terms. Are nonverbal visual stimuli, such as a person's face, remembered by first verbally describing the stimuli to oneself and then remembering the verbal description, as some researchers have suggested (e.g., Glanzer \& Clark, 1962, 1963, 1964; Haber, 1966)? Or is the stimulus information retained in some sort of visual or spatial format, as is implied by the term "visual image"?

The approach to this problem was direct. Nonverbal recognition memory performance was investigated when Ss were prevented from employing either a verbal memory code or a spatial memory code. The procedure used to prevent an $\mathrm{S}$ from utilizing particular codes for the nonverbal recognition stimuli involved requiring Ss to remember as many verbal memory items or spatial memory items as possible, while simultaneously performing the nonverbal recognition task.

The nature of the memory code for nonverbal stimuli will be inferred on the basis of whether the verbal memory-load condition or the spatial memory-load

*The experiments reported in this paper were part of a dissertation submitted in partial fulfillment of the $\mathrm{PhD}$ degree at the University of Michigan. I wish to acknowledge the help ful comments and criticisms of my Dissertation Committee Chairman, Professor D. J. Weintraub, and the other members of the Committee, Professors W. Kincaid, R. Pachella, and I. Pollack. I also wish to thank an anonymous reviewer who greatly aided in the conversion of the dissertation to journal form.

tReprint requests should be sent to Timothy A. Salthouse, Human Performance Center, 330 Packard Road, Ann Arbor,
Michigan 48104. condition causes the greater disruption in nonverbal recognition performance. If recognition performance is impaired more when Ss are prevented from using a verbal memory code (i.e., the verbal memory-load condition), then a verbal memory representation would be implicated for the nonverbal stimuli. However, if recognition performance is impaired more when Ss are unable to use a spatial representation for the nonverbal stimuli (i.e., the spatial memory-load condition), then a spatial memory code for the nonverbal stimuli would be implicated.

\section{GENERAL METHOD}

\section{Stimuli}

The choice of the stimuli for the recall task was dictated by several requirements: (a) The type of information that Ss would be required to remember had to be qualitatively different (i.e., verbal or spatial); (b) the formal structure of the task (i.e., the chance performance level, the information content per item, etc.) had to remain the same; and (c) the methods of presentation for the different types of information had to be either identical or very similar. Stimulus materials meeting all of these requirements are arrays of either 25 uppercase letters or 25 numbers. Only the letter arrays were used in Experiment $I$, but both letter and number arrays were used in Experiment II. The letter arrays consisted of all of the letters of the alphabet, except for the letter $O$, randomly arranged in a 5 by 5 square. The number arrays were composed of the 25 numbers, from 1 to 25 , positioned randomly in a diamond-shaped array. Both types of arrays are illustrated in Fig. 1.

The arrays were typed in the center of $127 \times 178 \mathrm{~mm}$ index cards, with white cards used for the letter arrays and yellow cards used for the number arrays. Each row or column was separated from its neighboring row or column by two typed spaces. Seven of the items in each array were circled in red ink and served as the target items. The target items for each array were selected randomly, with the restriction that each row or column had to have at least one, but not more than three, target items. Stimuli in which the positions of the target items formed a symmetrical or almost symmetrical pattern were excluded. In addition, the target items in the letter arrays used in Experiment II did not include any vowels to prevent Ss from 
(a)

12

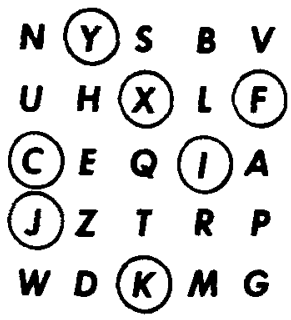

(08) 24 (16)

(02) 19211104

01151017230609

(18) 220325 (13)

05 (14) 20

07

(b)
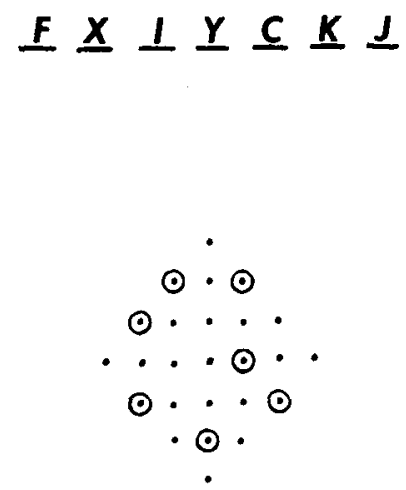

Fig. 1. Illustration of the stimulus arrays (a) and the array responses (b) used in the overlapping recall task. The letters in b are the responses to the square array in $a$, and the circled dots in $b$ are the responses to the diamond array in a.

coding the items into words, a strategy that was observed in Experiment I.

The Ss were instructed to remember either the positions or the identities of the target items. When Ss were remembering positions, they were given a response form containing either a square- or diamond-shaped array of 25 dots, depending upon whether they received the letter or number stimuli. The recall responses for the position information consisted of circling the dots in the response array that corresponded to the positions of the circled items in the stimulus array. The recall responses for the target identity information involved writing the seven target items in seven horizontal spaces provided on a response form. The recall score in both tasks was simply the number of target items reproduced correctly.

Recall instructions for both types of information emphasized that Ss were to guess, if necessary, to produce seven responses on each trial. In an attempt to reduce the variability of strategies used to handle the recall tasks, Ss were encouraged to use the "most effective strategy." The suggested strategy for remembering the target identities mentioned the "effectiveness" of verbal or auditory coding and rehearsal of the target items in increasing recall. The strategy suggested for the position task emphasized the "advantages" for remembering positions of generating and maintaining a visual image of the stimulus array. In addition, Ss were completely informed about the construction of the arrays, including details about the population of stimulus items and the fact that each item appeared only once in each array.

\section{Procedure}

The general experimental design is represented by the five trial types illustrated in Table 1. The two most important trial types are those designated IR and PR. In these trials Ss first saw a

stimulus array, next performed the recognition task with the nonverbal visual stimuli, and finally recalled the array information. The remaining trial types are control trials for the recognition task $(R)$ and for the recall tasks involving identity and position information ( $\mathrm{I}$ and $\mathrm{P}$, respectively). The presentation of a stimulus array in $R$ and the introduction of a distraction task requiring little or no memory involvement into the retention interval of $I$ and $P$ were attempts to equate the attention demands on $S$ in all trial types. In Experiment II these at tempts were abandoned and R, I, and P were "pure," involving only the recognition or recall task.

In order to avoid problems of differences in task emphasis, the Ss in both experiments were instructed that if they had difficulty handling both tasks in IR and PR, they were to emphasize the recall task and let their performance on the recognition task suffer if necessary.

\section{EXPERIMENT I}

The first experiment explored the effectiveness of the selective interference method as a means of determining the nature of the memory representation for nonverbal visual stimuli.

\section{Method}

Subjects. Thirty-six introductory psychology students participated for $1 \mathrm{~h}$ each in partial satisfaction of a course requirement. The $\mathrm{Ss}$ were assigned to one of three groups in the order they reported to the laboratory, with the constraint that each group result in six males and six females. All Ss were tested individually.

Stimuli. Three different types of stimuli were used in the experiment. The stimuli in the recognition task were a set of schematic faces originally constructed by Tversky (1969) and illustrated in that report. Three binary dimensions distinguished the faces, resulting in a total of eight different stimuli. The three dimensions were (a) head shape, i.e., a vertically oriented oval or a horizontally oriented oval; (b) eye type, i.e., shaded dark eyes or unshaded "open" eyes; and (c) mouth curvature, i.e., a straight line mouth or an upward curved "smiling" mouth.

The stimuli for the recall task were 50 different representatives of the letter-array stimuli described earlier. During the experimental session, each $\mathrm{S}$ started at a random point in the deck of 50 stimulus cards and cycled through the deck until all trials had been presented.

In addition to the face and letter-array stimuli, single three-digit numbers were also used in some of the experimental conditions to be described later.

Apparatus. The letter arrays were observed by Ss through a half-silvered (one-way) mirror attached to the front of a cardboard box. The viewing time of the stimulus cards was

Table 1

Diagram of the Structure of the Five Trial Types

\begin{tabular}{|c|c|c|c|}
\hline $\begin{array}{l}\text { Trial } \\
\text { Type }\end{array}$ & & Trial Structure & \\
\hline & & $($ Time $\rightarrow$ ) & \\
\hline \multirow[t]{2}{*}{$\mathbf{R}$} & (Stimulus) & Recognition & ( \\
\hline & ( Array ) & Task & ( \\
\hline I & $\begin{array}{l}\text { Stimulus } \\
\text { Array }\end{array}$ & $\begin{array}{l}\text { (Minimal Memory) } \\
\text { (Distraction Task) }\end{array}$ & $\begin{array}{l}\text { Recall Target } \\
\text { Identities }\end{array}$ \\
\hline$P$ & $\begin{array}{l}\text { Stimulus } \\
\text { Array }\end{array}$ & $\begin{array}{l}\text { (Minimal Memory) } \\
\text { (Distraction Task) }\end{array}$ & $\begin{array}{l}\text { Recall Target } \\
\text { Positions }\end{array}$ \\
\hline IR & $\begin{array}{l}\text { Stimulus } \\
\text { Array }\end{array}$ & $\begin{array}{c}\text { Recognition } \\
\text { Task }\end{array}$ & $\begin{array}{c}\text { Recall Target } \\
\text { Identities }\end{array}$ \\
\hline PR & $\begin{array}{l}\text { Stimulus } \\
\text { Array }\end{array}$ & $\begin{array}{c}\text { Recognition } \\
\text { Task }\end{array}$ & $\begin{array}{l}\text { Recall Target } \\
\text { Positions }\end{array}$ \\
\hline
\end{tabular}


limited by controlling the time that the interior of the box was illuminated by a $75-\mathrm{W}$ light bulb attached to the top of the box. Directly adjacent to the array presentation apparatus was a Scientific Prototype three-field tachistoscope used to display the schematic face stimuli and the three-digit number stimuli. The binocular viewer for the tachistoscope was located a short distance to the left of the viewing window of the array presentation apparatus, so that $S$ merely had to move his head slightly to switch from viewing the letter arrays to observing the face or number stimuli.

Procedure. The design of the experiment was oriented around two basic tasks, a letter-array recall task and a face recognition task. The letter-array task was as described above and involved remembering either verbal (i.e., identity) or spatial (i.e., position) information. The arrays were presented for a duration of $4 \mathrm{sec}$, with a retention interval of $10 \mathrm{sec}$. At the end of the retention interval, a red indicator light signaled $S$ to begin recall. The face recognition task involved a judgment of whether two successively presented schematic faces were the same or different. The faces were presented in the tachistoscope for $500 \mathrm{msec}$ each, separated by an interstimulus interval of $4 \mathrm{sec}$ (measured from the offset of the first face to the onset of the second). A bright field was exposed in the tachistoscope during the interstimulus interval to minimize the effects of image persistence and short-term visual storage phenomena. In addition to making a same/different response, Ss were also asked to attach a confidence rating to their decision by assigning to it one of the digits 1,2 , or 3 to indicate high, moderate, or low confidence, respectively. Both the same/different response and the confidence rating were to be made vocally immediately after the second face stimulus had been presented.

As mentioned earlier, the addition of a stimulus-array presentation in $\mathrm{R}$ and a minimal-memory distraction task in $\mathrm{I}$ and $\mathbf{P}$ were efforts to make these trial types approximately equivalent in attention demands to IR and PR. In order to force Ss to attend to the stimulus array in $R$, they were instructed to say "yes" if the letter "A" was a target item in that array and to say "no" if it was not. Additional instructions emphasized that no array information need be remembered and that the only response to the array should be made before the face stimuli were presented. The distraction task in I and $\mathrm{P}$ involved reading aloud a three-digit number exposed for $500 \mathrm{msec}$ in the tachistoscope. The number was presented at approximately the same point in the retention interval at which the first face stimulus was presented in IR and PR.

Although there were five different types of trials in the experiment, any given $S$ was presented with only three of them. All Ss first received 10 repetitions each of the two recall control trials, I and P, with the order counterbalanced across Ss. Next the Ss received 64 trials of $R$, IR, or PR, depending upon the group (Group N, V, or S, respectively) to which they had been assigned. The names of the groups were derived from the type of information (none, verbal, or spatial) the Ss were required to remember concurrent with the face recognition task.

The presentation order of the face recognition trials was varied across Ss, but all Ss ultimately received the same 64 trials. Half of these trials were same pairs, i.e., the two faces presented on those trials were the same, and half of the trials were different, i.e., the two faces in the pair were different. In addition, the different pairs were of three types, since the pair of faces could differ in one, two, or three dimensions. The number of trials with each difference relationship was 16 for pairs with a difference on one dimension, 12 for pairs with a difference on two dimensions, and 4 for pairs differing on all three dimensions. The distribution of same trials and of all types of different trials was approximately random throughout all stimulus presentation sequences.

\section{Results and Discussion}

Table 2 presents the means and estimated standard errors of the mean number of correct target items recalled in $\mathrm{I}$ and $\mathrm{P}$ by the $\mathrm{Ss}$ in each of the three groups.
Table 2

Mean Recall Performance for Groups N, V, and S: Experiment I

\begin{tabular}{llllll} 
& \multicolumn{3}{c}{ Type of Information Remembered } \\
\cline { 2 - 3 } & \multicolumn{2}{c}{ Identities } & & \multicolumn{2}{c}{ Positions } \\
\cline { 2 - 3 } Trial Type: & $\mathrm{I}$ & $\mathrm{IR}$ & & $\mathrm{P}$ & PR \\
\hline \multirow{2}{*}{ Group N } & 5.24 & - & & 3.50 & - \\
& $(.23)$ & & & $(.19)$ & \\
Group V & 5.18 & 5.64 & & 3.80 & - \\
& $(.18)$ & $(.21)$ & & $(.27)$ & \\
Group S & 5.25 & - & & 3.73 & 4.10 \\
& $(.22)$ & & $(.29)$ & $(.32)$ \\
\hline
\end{tabular}

Note-Numbers in parentheses are estimates of the standard error of the mean.

Since seven targets were presented on each array, the highest possible score is 7.0 items. The finding that the three groups performed nearly identically on both I and $P$ provides some assurance that the random assignment of Ss to the three groups resulted in groups that were approximately equivalent in performance on two relevant tasks.

The major concern in the experiment was the effect on face recognition accuracy of having to remember simultaneously one of two different types of information. The measure of recognition accuracy employed was the area under the curve pitting percentage of accurate same judgments against the percentage of inaccurate same judgments, i.e., the $A_{\mathbf{g}}$ measure, derived by considering the different confidence ratings as successive decision criteria (see Pollack \& Hsieh, 1969; Pollack, Norman, \& Galanter, 1964). The pattern of results and the statistical decisions were identical for both the $A_{\mathbf{g}}$ measure and the measure of percent correct.

The means and estimated standard errors of the $A_{\mathrm{g}}$ measure of recognition accuracy were $.889(.032), .890$ (.028), and $.756(.036)$ for Groups $\mathrm{N}, \mathrm{V}$, and $\mathrm{S}$, respectively. It is obvious at first glance that Groups $\mathrm{N}$ and $\mathrm{V}$ are nearly equal and that both groups are superior to Group S. Statistical support for this conclusion is provided by a Kruskal-Wallis rank-order analysis of variance. The test was significant at the .01 level, and the rank sums $(\mathrm{N}=268.5, \mathrm{~V}=266$, and $\mathrm{S}=131.5)$ clearly indicate that Group $S$ is appreciably different from Groups $\mathrm{N}$ and $\mathrm{V}$, which are nearly equivalent.

A further analysis of the recognition performance was carried out in order to determine whether the groups differed in the manner in which they processed the face stimuli. For this analysis, an $A_{\mathbf{g}}$ measure was calculated separately for each type of different trial for each $\mathrm{S}$. The means of these data are illustrated in Fig. 2. The data were subjected to an arc-sine transformation to achieve homogeneity of variance and tested with an analysis of variance. Both the main effects of groups $[F(2,33)=6.90, p<.005]$ and of type of different trial $[F(2,66)=27.21, p<.001]$ were significant, but their interaction was not $(F<1.0)$. 


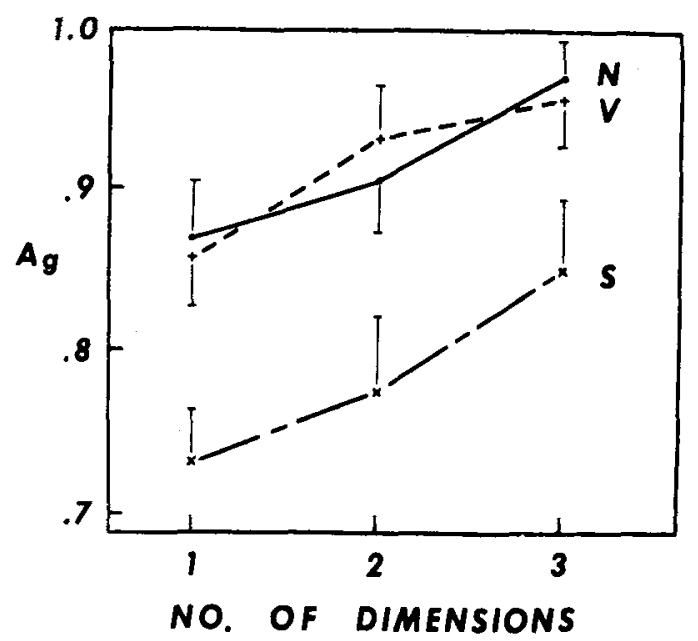

Fig. 2. $A_{g}$ for different trials with one, two, and three dimensions different, Experiment I. (The bars above or below each point indicate the estimated standard errors.)

These results indicate (a) that all three groups are discriminating among the types of different trials, finding it easier to detect a difference when the pair of stimuli had a greater number of dimensions different, and (b) that Groups N, V, and S maintain their same relative standings for all forms of different trials. The latter fact further demonstrates that the poorer performance of Group $S$ is not limited to any particular kind of recognition trial.

An additional analysis of the data on the basis of which features were different in the different trials (e.g., eyes, head shape, eyes and mouth, etc.) yielded no differences among the groups in the relative emphasis on one feature or another and no interaction of Kind of Feature by Recall Group.

The results discussed thus far make it abundantly clear that having to remember position information, while simultaneously performing a face recognition task, causes much more interference in the face recognition performance than having to remember identity information. This finding is pertinent to all of the goals of the current project. First, because the interference is selective and in the direction of spatial information interfering and verbal information not interfering, the memory representation for the schematic face stimuli used in the recognition task is inferred to be spatial in nature. Second, the notion that spatial and verbal. information can be maintained in memory simultaneously is supported by the lack of substantial interference between the verbal recall task and the spatial face recognition task. And third, evidence in favor of the separate-system hypothesis is provided in both of the results just described.

It is possible, however, that the findings reported above were the result of one or more artifacts. For example, since position information was more difficult to remember than identity information (compare $\mathrm{I}$ and $\mathbf{P}$ trials in Table 2), the position recall task may have caused more interference in recognition performance, either because less emphasis was placed on the recognition task in $P R$ than in IR or because the more difficult position task required more central processing capacity than did the identity task.

A priori, there is no reason to expect a difference in task emphasis, since both Groups $\mathrm{V}$ and $\mathrm{S}$ were instructed to emphasize the recall task over the recognition task. Nevertheless, this possibility can be checked by means of the following comparison. Since performance measures are available both when the recall task is performed alone and when it is performed concurrently with the recognition task, one can compare the differences in performance between single-task trials and dual-task trials for the two recall groups. That is, the difference between performance on I and IR can be compared to the difference between performance on $P$ and PR. If the Ss in Group S were placing more emphasis on the letter-array recall task in the dual-task situation than were the Ss in Group V, the Group S difference would be expected to be greater than the Group V difference.

A potentially critical issue concerns whether the differences to be compared are absolute or relative differences. Absolute differences are simply the total number of items different between the IR and I trials and the PR and $P$ trials. Relative differences conditionalize the amount of the difference upon the single-task or base performance level in each group. Thus, the relative difference scores would be ratios in the form $(I-I R) / I$ and $(P-P R) / P$. It is quite probable that convincing theoretical arguments could be offered in behalf of each of the two methods of difference comparison. For this reason, both comparisons are presented below.

The mean absolute differences were -.38 for Group $S$ and -.47 for Group $V$, with estimated standard errors of .22 and .19 , respectively. The means and estimated standard errors of the relative differences or ratios were -.13 and .07 for Group $S$ and -.10 and .04 for Group V. Clearly, with neither difference comparison is the Group $S$ difference significantly larger than the Group V difference. On the basis of this evidence, therefore, the suggestion that the differences between Groups $V$ and $S$ could be due to a difference in task emphasis must be rejected. The fact that the differences were negative is of no consequence to the logical argument and is probably attributable to practice effects, since the estimates of single-task performance were based on trials fewer in number and presented earlier in the session than those used in estimating the performance in the dual-task situation.

\section{EXPERIMENT II}

Experiment II was designed to test the second hypothesis that remembering position information causes more interference in a nonverbal recognition task merely because target positions are more difficult to remember than target identities. Four major conditions 
were involved, consisting of the combination of two types of recognition information (i.e., either nonverbal or verbal) with two types of recall information (i.e., either target identities or target positions).

According to the selective interference hypothesis, remembering position information interferes with recognition performance because of the spatial nature of the recognition task. If a verbal recognition task were to be used, remembering identity information would be expected to result in more interference than remembering position information. Thus, the selective interference hypothesis predicts a significant interaction between the type of recognition information and the type of recall information.

If the other hypothesis is correct, i.e., attributing the greater interference of position information to the greater difficulty of remembering target positions compared to target identities, then remembering positions should cause more interference than remembering identities, regardless of the type of recognition information. That is, this hypothesis predicts a significant main effect of the type of recall information (i.e., position recall should cause more interference than identity recall) but no significant interaction.

An additional purpose of the experiment was to investigate the influence of practice on the magnitude of the experimental effects. To this end, each $\mathrm{S}$ performed in two sessions under the same experimental conditions.

\section{Method}

Subjects. Fortyeight Ss received $\$ 2 / \mathrm{h}$ for their participation in two experimental sessions lasting from 1 to $2.5 \mathrm{~h}$. The Ss were tested in groups of from one to four in two sessions separated by $24 \mathrm{~h}$. Three experimental groups of $16 \mathrm{Ss}$ each, 10 females and 6 males, were formed by assigning Ss to one of the three groups in the order they reported to the laboratory.

Stimuli. One hundred and twenty slides of 13 model airplanes photographed in various orientations against a blue background were used as the nonverbal stimuli. Sixty slide pairs were "same" pairs and had the same airplane in the same orientation in both slides. The remaining 60 pairs were "different" pairs in the sense that the airplanes, although in the same orientation and very similar in general appearance, were actually different airplanes.

The verbal stimuli were 120 pairs of slides of three four-letter words. Each pair of slides contained a different set of words, and in all slides the three words were typed in lowercase on three lines, each directly below the one above. Half of the pairs of slides had the same three words, in the same order, in both members of the pair. The other 60 pairs of slides had one word different between the members of each pair. The different word was randomly varied among the first, second, and third positions on the slide.

Both the letter-array and the number-array stimuli described previously were used in the current experiment. Each type of array had 160 different versions, this being sufficient to allow a different version to be presented to a given $S$ on each trial.

Apparatus. A Kodak Carousel 350 slide projector with an automatic slide changer was used to project the recognition stimuli on a wall. The two slides on each trial were exposed for approximately $1.5 \mathrm{sec}$ each, with the blank interval between the two slides lasting approximately $3.0 \mathrm{sec}$.

As in the previous experiment, two interval timers were used to control the stimulus presentation time $(4 \mathrm{sec})$ and the retention interval $(10 \mathrm{sec})$ for the recall task. The stimulus presentation time was regulated by the duration of a clicking sound that signaled $S$ to inspect the letter array.

Procedure. The design of the experiment was similar to that of Experiment $I$ in that all $S$ s received Trial Types $I$ and $P$, and three groups of Ss were differentiated according to whether they received Trial Type R, IR, or PR. As in Experiment I, the three groups were designated Groups $\mathrm{N}, \mathrm{V}$, and $\mathrm{S}$, respectively.

The $S$ s in all groups received both nonverbal and verbal recognition stimuli and participated for a total of 160 trials in each of two sessions. The composition of the trials was as follows: 10 initial trials each of $I$ and $P, 60$ trials of $R, I R$, or PR with airplane recognition stimuli, 60 additional trials of the same type with word recognition stimuli, and, finally, 10 more trials each of $I$ and $P$. The presentation order of $I$ and $P$ and of the airplane and word recognition stimuli was counterbalanced across Ss within each group and across sessions for each $\mathrm{S}$. Furthermore, in each session a new set of recognition stimuli and a different form of recall stimuli (i.e., square-shaped letter arrays or diamond-shaped number arrays) were employed.

Responses to the recognition task were made by S's writing in the appropriate space on the response form either the letter "S" for slide pairs that were the same or the letter " $D$ " for slide pairs that were different, and a confidence rating from 1 to 3 . Both the letter and number responses were to be written immediately after the second slide had been presented.

\section{Results and Discussion}

Recall performance in $I$ and $P$ was measured four times for each $S$ in the current experiment. In both experimental sessions, 10 trials were presented at the beginning and at the end of the session. The group means and estimated standard errors for the 20 trials in each session are presented in Table 3 .

Although there are some anomalies in the data, the two groups of most importance in subsequent analyses, i.e., Groups $\mathrm{V}$ and $\mathrm{S}$, have very similar performance on Trial Types $I$ and $P$ in both sessions.

Table 4 summarizes the means and estimated standard errors of the $A_{g}$ recognition accuracy measure for the

Table 3

Mean Recall Performance for Groups N, V, and S: Experiment II

\begin{tabular}{|c|c|c|c|c|c|c|}
\hline \multirow[b]{3}{*}{ Trial Type: } & \multicolumn{6}{|c|}{ Type of Information Remembered } \\
\hline & \multicolumn{3}{|c|}{ Identities } & \multicolumn{3}{|c|}{ Positions } \\
\hline & I & $\begin{array}{c}\text { IR } \\
\text { Air- } \\
\text { planes }\end{array}$ & $\begin{array}{c}\text { IR } \\
\text { Words }\end{array}$ & $\mathbf{P}$ & $\begin{array}{l}\text { PR } \\
\text { Air- } \\
\text { planes }\end{array}$ & $\begin{array}{c}\text { PR } \\
\text { Words }\end{array}$ \\
\hline & \multicolumn{6}{|c|}{ Session 1} \\
\hline Group N & $\begin{array}{l}5.53 \\
(.17)\end{array}$ & - & - & $\begin{array}{c}4.20 \\
(.19)\end{array}$ & - & - \\
\hline Group V & $\begin{array}{l}5.81 \\
(.22)\end{array}$ & $\begin{array}{l}5.50 \\
(.27)\end{array}$ & $\begin{array}{c}4.93 \\
(.31)\end{array}$ & $\begin{array}{c}4.37 \\
(.25)\end{array}$ & - & - \\
\hline \multirow[t]{2}{*}{ Group $S$} & $\begin{array}{l}5.96 \\
(.19)\end{array}$ & - & - & $\begin{array}{c}4.36 \\
(.24)\end{array}$ & $\begin{array}{l}3.94 \\
(.27)\end{array}$ & $\begin{array}{l}4.04 \\
(.25)\end{array}$ \\
\hline & \multicolumn{6}{|c|}{ Session 2} \\
\hline Group N & $\begin{array}{l}5.75 \\
(.15)\end{array}$ & - & - & $\begin{array}{c}4.40 \\
(.13)\end{array}$ & - & - \\
\hline Group V & $\begin{array}{l}5.93 \\
(.18)\end{array}$ & $\begin{array}{l}5.64 \\
(.26)\end{array}$ & $\begin{array}{c}5.40 \\
(.24)\end{array}$ & $\begin{array}{c}4.99 \\
(.24)\end{array}$ & - & - \\
\hline Group S & $\begin{array}{l}5.98 \\
(.16) \\
\end{array}$ & - & - & $\begin{array}{r}5.06 \\
(.23) \\
\end{array}$ & $\begin{array}{r}4.63 \\
(.26) \\
\end{array}$ & $\begin{array}{c}4.45 \\
(.27) \\
\end{array}$ \\
\hline
\end{tabular}

Note-Numbers in parentheses are estimates of the standard error of the mean. 
Table 4

Mean Recognition Accuracy ( $A_{g}$ Measure) for Groups N, V, and S: Experiment II

\begin{tabular}{|c|c|c|c|c|}
\hline \multirow[b]{2}{*}{$\begin{array}{c}\text { Recog- } \\
\text { nition } \\
\text { Material }\end{array}$} & \multirow[b]{2}{*}{$\begin{array}{l}\text { Trial } \\
\text { Type: }\end{array}$} & \multirow{2}{*}{$\begin{array}{c}\text { Group N } \\
\text { Type of } \\
\begin{array}{c}\text { None } \\
\text { R }\end{array}\end{array}$} & \multirow{2}{*}{$\begin{array}{c}\begin{array}{c}\text { Group V } \\
\text { Informatio }\end{array} \\
\begin{array}{c}\text { Identities } \\
\text { IR }\end{array}\end{array}$} & \multirow{2}{*}{$\begin{array}{c}\begin{array}{c}\text { Group S } \\
\text { nentbered }\end{array} \\
\begin{array}{c}\text { Positions } \\
\text { PR }\end{array}\end{array}$} \\
\hline & & & & \\
\hline & & \multicolumn{3}{|c|}{ Session 1} \\
\hline Airplanes & & $\begin{array}{c}.899 \\
(.019)\end{array}$ & $\begin{array}{c}.822 \\
(.022)\end{array}$ & $\begin{array}{c}.824 \\
(.023)\end{array}$ \\
\hline \multirow[t]{2}{*}{ Words } & & $\begin{array}{c}.976 \\
(.005)\end{array}$ & $\begin{array}{c}.884 \\
(.015)\end{array}$ & $\begin{array}{c}.929 \\
(.015)\end{array}$ \\
\hline & & \multicolumn{3}{|c|}{ Session 2} \\
\hline Airplanes & & $\begin{array}{c}.930 \\
(.015)\end{array}$ & $\begin{array}{c}.842 \\
(.026)\end{array}$ & $\begin{array}{c}.830 \\
(.016)\end{array}$ \\
\hline Words & & $\begin{array}{c}.984 \\
(.006)\end{array}$ & $\begin{array}{c}.867 \\
(.020)\end{array}$ & $\begin{array}{c}.923 \\
(.015)\end{array}$ \\
\hline
\end{tabular}

Note-Numbers in parentheses are estimates of the standard error of the mean.

three groups of Ss in Sessions 1 and 2. (The pattern of results and statistical findings utilizing percent correct as the dependent measure were the same as those with the $A_{g}$ measure.)

The data in Table 4 indicate that the accuracy of recognizing both airplanes and words is lower in both sessions for Groups $\mathrm{V}$ and $\mathrm{S}$ than for Group N. That is, both types of recall information result in some decrement in recognition performance compared to a control condition in which no recall information was remembered. No clear explanation is available for the discrepancy between this finding and the almost complete lack of interference of remembering identity information on face recognition reported in Experiment I.

In order to determine whether the amount of interference in recognition performance was different when different types of recall information were remembered, the data from Groups $\mathrm{V}$ and $\mathrm{S}$ were tested for statistical significance. A three-factor (recall type, recognition type, and session) analysis of variance was conducted on the arc-sine transformed data.

The results were as follows. Neither the main effect of type of recall information $[F(1,30)=1.85]$ nor of session $(F<1.0)$ was significant, but the main effect of type of recognition material was highly significant $[F(1,30)=19.26, p<.001]$. The interaction of Type of Recall Information by Type of Recognition Material was also of a magnitude unlikely to have occurred by chance $[F(1,30)=4.55, p<.05]$, but none of the other interactions even approached statistical significance $(\mathrm{F}<1.0)$.

The finding of a significant interaction of Type of Recall Information by Type of Recognition Material provides support for the selective interference hypothesis and its interpretation of the results of Experiment I. Remembering identity information interferes more with word recognition than with airplane recognition, while the reverse is true for remembering position information. That is, the interference is selective and dependent upon the types of information involved in the two concurrent tasks.

As in the previous experiment, the recall data were analyzed by comparing the performance on Trial Types I and $\mathbf{P}$ with performance on Trial Types IR and PR. Both the absolute and the relative difference measures discussed earlier were subjected to the same type of analysis of variance performed on the recognition data. The statistical results were identical in both difference measures and, hence, only those for the absolute measure will be reported. Neither the main effects of recall type nor of session were statistically significant $(\mathrm{F}<1.0)$, and both the type of recognition material $[\mathrm{F}(1,30)=17.18, \mathrm{p}<.001]$ and the interaction of Recall Type by Recognition Material $[\mathrm{F}(1,30)=11.23$, $\mathrm{p}<.01]$ were significant. The triple interaction of Recall Type by Recognition Material by Session was also significant $[F(1,30)=5.82, p<.05]$. The interactions of Session by Recognition Material $(F<1.0)$ and Session by Recall Type $[F(1,30)=3.18]$ were not statistically significant.

Several of the results of this analysis are worthy of comment. First, the finding of significant effects in the recall data indicates that the interference in the current experiment is manifested in both recall and recognition performance. Second, the significant interaction of Recall Type by Recognition Material is in the same direction as that present in the recognition data and, hence, considerably strengthens the support for the selective interference hypothesis. And finally, the significant triple interaction, taken in conjunction with the pattern of results in Table 3, indicates that the Recall Type by Recognition Material interaction disappears on Session 2. This last finding seems to suggest that practice diminishes the magnitude of the experimental effects. However, while the interaction disappears on Session 2 with the recall data, inspection of Table 4 indicates that the recognition data exhibit a stronger interaction in Session 2 than in Session 1. Thus, it appears that at present there simply is not enough evidence to warrant a conclusion about the influence of practice in the current experimental situation.

A final analysis was conducted on the recognition performance when the data were discarded from Ss who, in a postexperimental questionnaire, admitted that they named 3 or more of the 13 airplanes. The results of this test paraileled those from the analysis of variance on the recognition data from all of the Ss, but the probability that the Recall Type by Recognition Material interaction could have occurred by chance decreased from $p<.05$ to $p<.01$. This analysis, thus, indicates that the findings reported above are not caused by intergroup differences in airplane naming ability.

At the conclusion of the second experimental session, Ss were asked to rate, on a 5-point scale, the degree to which they relied on a verbal rehearsal or a visual image strategy for remembering target identities and target 
positions. The mean ratings, where 1 represented exclusive reliance on visual imagery and 5 represented exclusive reliance on verbal rehearsal, were 4.51 for identity information and 2.40 for position information. Only $1 \mathrm{~S}$ out of 48 failed to report a more "verbal" strategy for remembering identities than for remembering positions. The close agreement between this introspective evidence and one's intuitive feelings about the identity and position tasks strengthens the confidence one may have in the assertion that identity information is remembered verbally and position information is remembered spatially or visually.

The conclusions to be drawn from the results of the current experiment are as follows. First, the selective interference hypothesis is generally supported and, hence, so also is the selective interference interpretation of the results of Experiment I. The results clearly lead to the rejection of the hypothesis that position information is simply more demanding and, therefore, causes more general interference than identity information. This conclusion is based upon the recognition and recall results in Tables 3 and 4 , both of which exhibit a statistically significant interaction of Type of Recall Information by Type of Recognition Material. In addition, none of the analyses yielded a significant main effect of type of recall information, nor is there a pattern in this direction in any of the data.

A second conclusion is that airplane photographs are represented in short-term memory in a visual or spatial format. This is inferred from the fact that there is generally more interference when recognizing airplanes and remembering position information than when recognizing airplanes and remembering identity information.

The third conclusion is that further support is provided for the assumptions that verbal and spatial information can be represented in memory simultaneously and that each type of information is stored in a separate and independent memory. The success of the selective interference method of determining the memory code for nonverbal stimuli implies the probable existence of separate verbal and spatial information-processing systems that can act concurrently with minimal interference.

\section{GENERAL DISCUSSION}

The experiments reported above provide an unequivocal answer to the question of what the modality of the internal representation is, or at least can be, for nonverbal visual stimuli. A spatial or visual representation is clearly implicated, at least for unfamiliar complex stimuli or briefly presented simple stimuli.

The importance of the present results is accentuated by the lack of conclusive findings from studies using a selective interference procedure very similar to that employed here but investigating verbal rather than nonverbal stimuli. Two experiments (Atwood, 1971;
Bower, 1970) produced results indicating that a spatial or imaginal representation was possible for verbal stimuli, but subsequent unpublished experiments (e.g., Brooks, 1972; Bower, Munoz, \& Arnold, 1972; both cited in Anderson \& Bower, 1973) have failed to replicate the crucial findings. The current experiments demonstrate that a spatial representation is definitely possible for some stimuli, viz., nonverbal stimuli, and suggest that verbal and nonverbal stimuli are fundamentally different in their types of memory representation.

In demonstrating that nonverbal stimuli are retained in a visual or spatial mode, the current experiments are also relevant to the issue of visual imagery. It is obvious that the first step necessary for the investigation of visual imagery is the establishment of the existence of visual images. Such evidence for the existence of a visual image is available in the results reported above if one takes the reasonable position that a visual image is merely the spatial representation of information not physically present in the environment. An important point to note is that, in supplying data pertinent to the issue of visual imagery, objective rather than subjective methods of investigation were employed. That is, the conclusions in the present experiments were based upon inferences from performance measures and not on solely introspective reports, as was the practice in the early, and generally unfruitful, studies of imagery.

\section{The Assumption of Separate Memory Systems}

In general, the current experimental findings suggest that the assumption of independent memory systems is not only plausible but, in fact, probable. The primary support for the notion of separate memories is the selective interference found when different types of recall information are remembered concurrently with different types of recognition information. In both Experiments I and II, the most interference results when the same type of information is involved in the two simultaneous tasks. The interference is either greatly reduced or eliminated when different types of information are involved in the two tasks.

Before completely accepting the view that there are separate and distinct processing systems, it is essential to examine carefully the alternatives to this idea. One quite plausible alternative is that there is only a single unitary processing system and that interference within the system is proportional to the degree of similarity between the different pieces of information being processed.

However, an initial problem with a single similarity-dependent interference system is that the concept of similarity does not appear to do justice to the relationship among the stimuli in the current experiments. One's intuition suggests that the stimuli differ more in the type or quality of the information involved, rather than in terms of a structural or stimulus-determined notion of similarity. For example, it is difficult to conceive of how or why the schematic 
face stimuli of Experiment I would be judged more similar to a set of locations in a square than to a set of visually presented letters. Or consider the stimuli in Experiment II. Is it really the case that the airplane stimuli resemble a set of locations in an array more than the word stimuli and that this pattern of "resemblance" is reversed when a set of letters or numbers is substituted for the set of locations? The implausibility of this suggestion argues for a qualitative rather than a quantitative distinction among the stimuli and, hence, for the idea that there are at least two distinct information-processing systems. It might be noted that, even if the single processing system alternative were viable, the low levels of interference across, compared to within, information "types" indicate that the different types of information are processed in a functionally distinct manner, if not in a structurally distinct one.

Data relevant to the concept of a unitary memory and processing system are available from correlational analyses conducted on the results of the present experiments. First, consider the correlations between the performance on the two simultaneous tasks either computed for average performance on all trials across $\mathrm{Ss}$ or on a trial-by-trial basis for each $\mathrm{S}$. If a single processing system were involved in both tasks, one would expect these correlations to be relatively large and negative in sign. That is, if both tasks require the use of the same memory system, then it would be expected that good performance on one task could only be achieved at the expense of poor performance on the other concurrent task. In fact, however, none of the correlations between recall and recognition performance were significantly different from zero.

A second analysis involved computing correlation coefficients between the values for each $S$ of the mean number of identity items recalled in Trial Type I and the mean number of position items recalled in Trial Type $P$. The rationale behind this analysis was that, if a single memory were responsible for remembering both position and identity information, then one would expect large positive correlations between the estimates of identity memory capacity and position memory capacity. On the other hand, if more than one memory system were involved, one would expect generally low nonsignificant correlations.

The values of the identity-position recall correlations were +.315 for Experiment I and +.352 for Experiment II. Both correlations are, therefore, positive, but only the one from Experiment II was significantly different from zero $(\mathrm{p}<.05)$.

For purposes of comparison, correlations were also computed from the recall data in Experiment II between recall performance with the same type of information at two different points in time. The average within-session correlations (mean of first 10 trials vs mean of last 10 trials) were +.803 and +.644 for identity and position information, respectively. The average across-session correlations (mean of 20 trials on Session 1 vs mean of 20 trials on Session 2) were +.587 for identity information and +.557 for position information.

The important point to be noted is that all of the correlations reported above are larger than the largest of the correlations between different types of information (i.e., +.352), indicating that the strength of the relationship between the two estimates of memory capacity is much greater when the same type of information is involved. Moreover, since a certain amount of positive correlation might be expected because of motivational differences across Ss, even the weak relationship that appears to exist between different types of information may be suspect.

The conclusion that must be reached from the correlation analysis just described is that only very weak, if any, support for the single memory system idea is provided. In fact, the results appear to be as consistent with the multiple memory hypothesis as they are with the hypothesis of a unitary memory.

It is clear that considerable evidence exists to support the idea that different types of information are stored and processed in distinct information-processing systems. This conclusion is consistent not only with the results of the present experiments but also with the results of experiments by other researchers (e.g., Brooks, 1967, 1968, 1970; den Heyer \& Barrett, 1971; Meudell, 1972; Murray \& Newman, 1973). If upheld, this conclusion will require that current theories of information processing and memory be considerably revised or extended. For example, almost all present memory theories are based entirely on research with verbal stimulus material, and nonverbal stimulus material is either completely neglected or it is assumed that nonverbal memory can be subsumed under the same principles postulated for verbal memory. The demonstration that different types of information are stored and processed in separate systems will necessarily have a substantial effect on this situation.

\section{REFERENCES}

Anderson, J. R., \& Bower, G. H. Human associative memory. Washington, D.C: Winston, 1973

Atwood, G. An experimental study of visual imagination and memory. Cognitive Psychology, 1971, 2, 290-299.

Bower, G. H. Analysis of a mnemonic device. American Scientist, 1970, 58, 496-510.

Brooks, L. R. The suppression of visualization by reading. Quarterly Journal of Experimental Psychology, 1967, 19, 289-299.

Brooks, L. R. Spatial and verbal components of the act of recall. Canadian Journal of Psychology, 1968, 22, 349-368.

Brooks, L. R. An extension of the conflict between visualization and reading. Quarterly Journal of Experimental Psychology, $1970,22,91-96$.

den Heyer, K., \& Barrett, B. Selective loss of visual and verbal information in STM by means of visual and verbal interpolated tasks. Psychonomic Science, 1971, 25, 100-102.

Glanzer, M., \& Clark, W. H. Accuracy of perceptual recall: An analysis of organization. Journal of Verbal Learning \& Verbal Behavior, 1962, 1, 289-299.

Glanzer, M., \& Clark, W. H. The verbal loop hypothesis: Binary 
numbers. Journal of Verbal Learning \& Verbal Behavior, $1963,2,301-309$.

Glanzer, M., \& Clark, W. H. The verbal loop hypothesis: Conventional figures. American Journal of Psychology, 1964, 77, 621-626.

Haber, $R$. Nature of the effect of set on perception. Psychological R eview, 1966, 73, 335-351.

Meudell, P. R. Short-term visual memory: Comparative effects of two types of distraction on the recall of visually presented verbal and non-verbal material. Journal of Experimental Psychology, 1972, 94, 244-247.

Murray, D. J., \& Newman, F. M. Visual and verbal coding in short-term memory. Journal of Experimental Psychology, $1973,100,58-62$.

Pollack, I., \& Hsieh, R. Sampling variability of the area under the ROC curve and of $d_{e}^{\prime}$. Psychological Bulletin, 1969, 71, 161-173.

Pollack, I., Norman, D. A., \& Galanter, E. An efficient nonparametric analysis of recognition memory. Psychonomic Science, 1964, 1, 327-328.

Tversky, B. Pictorial and verbal encoding in a short-term memory task. Perception \& Psychophysics, 1969, 6, 225-233.

(R eceived for publication February 1, 1974; revision received A pril 22,1974 .) 